\title{
Advanced Digestive System Neuroendocrine Neoplasm
}

National Cancer Institute

\section{Source}

National Cancer Institute. Advanced Digestive System Neuroendocrine Neoplasm. NCI

Thesaurus. Code C158089.

A digestive system neuroendocrine neoplasm that has spread extensively to other anatomic sites or is no longer responding to treatment. 